\title{
A Study on the Role of Human Element (Staffs) in Marine Accidents
}

\author{
Reza Karimpour ${ }^{1}$, Zahra Karimpour ${ }^{2}$ \\ ${ }^{1}$ I.R of Iran Shipping Line (IRISL), Tehran, Iran \\ ${ }^{2}$ Shahid Bahonar Universitym, Kerman, Iran \\ Email:rezakarimpour61@gmail.com,zarakarimpour@gmail.com
}

Received 15 June 2016; accepted 10 July 2016; published 13 July 2016

Copyright (C) 2016 by authors and Scientific Research Publishing Inc.

This work is licensed under the Creative Commons Attribution International License (CC BY). http://creativecommons.org/licenses/by/4.0/

(c) (7) Open Access

\begin{abstract}
Ships usually operate in the vibrant and dynamic environment; a majority of crews work and have a rest in a stressful space and have daily job displacements that working in it and moving from port disrupt as soon as reaching to port. Such conditions which require living at work place for a long time raises a unique job life which causes increase in risks of human mistakes. Huge marine accidents occur per year in country in which human element plays a major role. Identification and analysis of the components affect individuals as the staffs in ships, so that such component raises the conditions due to inattention which result in rise of severe and more severe marine accidents. Evaluation of each component has been taken into account in the present research. The present research seeks to examine and identity factors affecting human elements in marine accidents.
\end{abstract}

\section{Keywords}

\section{Staffs, Human Element, Marine Accidents, Human Mistakes, Job Life}

\section{Introduction}

Numerous marine accidents due to human error cause the damage to property and life as well as marine environment. For instance, in 2007 over 300 marine accidents have taken place in country in which human has played a major role, resulted in serious threat to human life in addition to financial loss. In most of marine accidents, damage to marine environment has occurred. Humans involve in the maritime industry at various levels from design and build of a ship to guide, use and coastal management of the whole human presence.

It is observed that a wide range of affairs are accomplished by human element [1].

On the other hand, latent unsafe conditions in management processes intensify the necessity to attention to the issue, i.e. there are conditions in the process of administration of organizational affairs which remain latent and 
reveal at required time raising accident [2]. Analysis of marine accidents at thirty years ago indicates that all the marine accidents almost associate to human elements regarding the individuals' involvement in affairs and aspects related to maritime and the factor causing over $90 \%$ of marine accidents relates directly or indirectly to humans. Human error is considered as the most important cause of accidents that international maritime organization calls the key role of human elements in rise of marine accidents. The man develops the main focus of affairs in marine activities and human element at marine environment from job and biological perspective face the limitations which have caused maleficence and lack of required stability for marine staffs. Therefore, detection of the parameters which play a major role in human error is of great importance [3] [4]. The main problem of this research lies on detecting factors affecting human elements, thus the main question of research is whether human elements affect occurrence of marine accidents.

By detecting and understanding the factors raising a marine accident and providing countervailing measures, it can prevent from the same cases in future.

Therefore, addressing the components which relate to humans and detecting them can be effective in prevention from future accidents. In this regards, the present research seeks to find the causes for marine accidents which derive from human elements [5].

\section{Significance of Research}

Significance of this research lies on this fact that since detecting the causes of marine accidents plays a major role in prevention from them in future, study on subject of research has been doubled in importance. The motivation to select subject of research is that the researcher has worked at marine environment and has informed of the ship and human elements that are employed in the marine environment as well as how the activities of human elements are at ships and the environment in which the staffs work and have a rest. Statistics of some European leading insurance companies indicate that marine accidents in which the human element has played role have been numerous with an ascending trend. Reports of insurance companies indicate that the accidents in which the human elements have a special role keep increasing. According to what said above, it can perceive that quality of manpower who work in ships affects accidents, thus the significance of research by addressing human elements causes marine accidents [6]-[8].

\section{Literature Review}

The related works in Iran under subject of research were examined through various websites and sources. In this regards, scientific documentation site of Iran in which the academic theses of country have been collected was examined and various theses were examined.

\section{Study on Mental and Environmental Pressures and Their Linkage with Accidents in Saipa Firm}

This master thesis refers to the most important factors which cause stress in the workplace and examines and analyzes the relationship between stress and accidents at Saipa firm. The related factors have been classified to two groups and these factors have been measured in form of two major hypotheses and seven secondary hypotheses. Questionnaire has been used to test hypotheses. The research findings are as follows:

\section{Stress Affects Adverse Accidents}

The correlation between stress and adverse accidents has equaled to 0.69 which is significant at $\alpha=0.01$.

The organizational factors result in increasing stresses among staffs. The correlation between organizational factors and stresses in staffs has equaled to 0.85 which is significant at $\alpha=0.01$.

The environmental factors result in increase of stresses among staffs. The correlation between environmental factors and stresses in staffs has equaled to 0.68 which is significant at $\alpha=0.01$.

According to the investigations, articles and studies below on human errors, job stress and accidents from humans' action, the subjects below have been identified, brought with the summary as follow; yet no study has been conducted in the context of human factors and accidents, the present research can be the starting point in Iran. However, the research indices which are supposed to be measured have been selected in a way that they can be used as the results of research worldwide [8]. 


\section{Detection and Analysis of Human Errors via PHEA in an Industrial Unit}

In the present research, the authors have examined the accidents caused by human factors. It has been mentioned that over $90 \%$ of industrial accidents directly or indirectly relate to human factor, so that the human error has been considered as the most important cause of accidents. Further, occurrence of large events like Felix Bureau (England 1976) (Three Mile Island) America-1979 (Bhopal) India-1984 (Chernobyl) Russia 1986 and many other events due to human errors reflects the importance and role of man in accidents. In this study which was conducted in an industrial unit, after studying all the job duties of the individuals, interviewing with supervisors and staffs at unit and examining the past accidents at unit, the job duties susceptible to human errors were selected. Then, each of job duties were analyzed via H. T. A method and result from analysis was proposed in charts and then at the next stage a variety of human errors were predicted and identified and deviation of each from the normal status was specified via a series of guide words [9] [10].

\section{Research Hypotheses}

H1: Software component of human element affects marine accidents.

H2: Hardware component of human element affects marine accidents.

H3: Environmental component of human element affects marine accidents.

H4: Bioware component of human element affects marine accidents.

\section{Conceptual Model of Research}

The model has four major components which develop major components of human element including:

-Software Component

-Hardware Component

-Environmental Component

-Bioware Component

Shell model displays four components above and determines the relationship between components and progresses step by step to find causes of an accident which is due to human function [11]-[13]. In analysis of the causes of an accident which is due to human error and function, this error does not fall from the mentioned components. Analysis of each of components and the relationship between the occurred accidents can assist for access to realities [14] (Figure 1).

\section{Research Method}

In the present research, descriptive survey has been considered as the research method. The existing information and reports in Ports and Shipping Organization regarding its responsibility for handling marine accidents and utilizing the individual experiences of the researcher as well as the sources in library of mentioned organization and the research in the context of factors affecting manpower at work environments have been used. Documents and websites of international organizations especially International Labor Organization and International Maritime Organization have been used. Further, the questionnaire has been used to collect the required data from the statistical population (Islamic Republic of Iran Shipping Line) and the research hypotheses have been tested via statistical techniques. Therefore, the researcher believes that it can examine and study the subject of research through this research method properly and achieve the predicted goals [15]-[17].

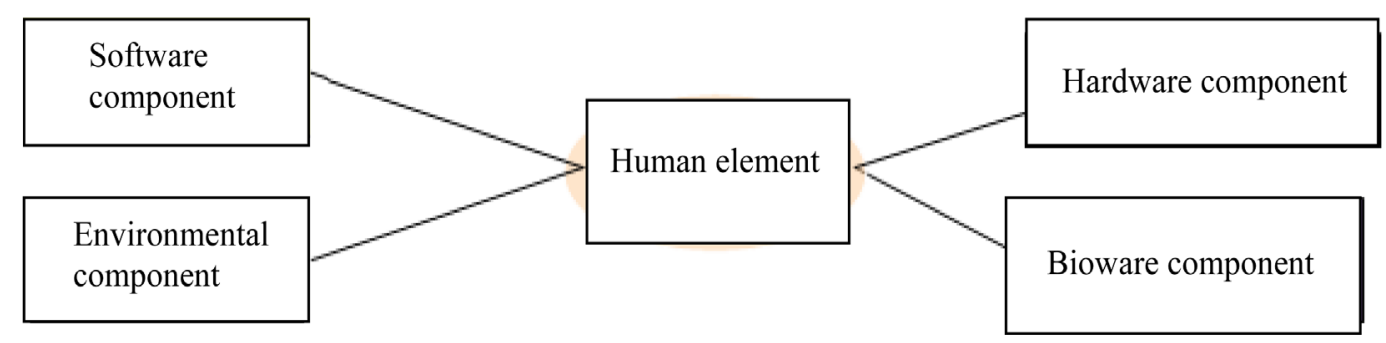

Figure 1. Conceptual model of research. 


\section{Research Scope}

The statistical population consists of all the commanders of ocean-going fleet vessels at IRISL, who operate in open sea.

\section{Theoretical Background}

\subsection{Human Factors}

The factors which merely relate to humans such as Abilities, skills, knowledge, personality (mental condition, emotional state), physical condition (physical health, addiction to drugs and alcohol, exhaustion), pre-disaster activities/events, tasks assigned to an accident/events, actual behavior at the time of accident/incident [14].

\subsection{Organized on Ship}

Organized on ship implies division of duties and responsibilities, composition of the crew (nationality/ability), number of crew, workload/complexity of tasks, working hours/rest hours, procedures and applicable instructions, communications (internal and external), management and supervision of the ship, organizing training on the ship and maneuvers, work group including resource management, planning such as trips, goods, maintenance [18].

\subsection{Living and Working Conditions}

Living and working conditions imply amount of built-in automatically devices, design of work, life and place of recreation and facilities, appropriate living conditions, leisure, adequate food, range of motion and movement of the ship, vibration, heat and noise [19].

\subsection{The Factors Related to Ship}

The factors related to ship which affect human element include: Design, status of maintenance, equipment (availability, reliability), characteristics of goods and cargo including cargo arrangements on the ship, displacement and protection of the goods, certificates [20].

\subsection{Coastal Management}

Coastal manager is in charge of organizing and administrating the affairs related to shipping and also in charge of the activities below for administration of shipping affairs:

\subsection{The Policy Related to Employment}

Security policy and its philosophy (culture, attitude and trust), management commitment in relation to safety, Vacation and Holiday Schedule, overall management policy, port Schedule and bespoke and industrial agreements, assign tasks, the vessel-land communication [11].

\subsection{External (Environmental) Effects}

The effects of external forces include the conditions of sea and air, transport conditions and Port conditions, traffic congestion, organizations representing ship owners and seafarers, regulations, inspections and such as international-national-port, Classification institutions Etc [21].

\section{Marine Accident}

Marine accident is called to an incident which results in cases below:

- Death or serious injury to the person or persons which had been occurred in relation to utilization of ship

- The loss or damage to persons caused by ship in connection with the performance of ship

- Loss, assumed loss or abandonment of ship

- Total damage to ship

- Failure to ship, ship involvement in collision

- Loss which raises in connection with performance of ship 
- Damage to environment which had been created by means of damage to the ship or ships [22]

\section{Findings of Research}

\section{The First Hypothesis Testing}

Software Component of Human Element Affects Marine Accidents

H0: at least $80 \%$ of respondents agree with the first hypothesis.

H0: utmost $80 \%$ of respondents disagree with the first hypothesis.

With regard to z-distribution table, extent of $\mathrm{z}$ extracted from table equals to -2.33 which is less than the calculated value, whereby $\mathrm{H} 0$ will be confirmed. Therefore, it can say at confidence level (99\%) that over $80 \%$ of respondents have confirmed the first hypothesis.

The second hypothesis testing

Hardware component of human element affects marine accidents.

H0: at least $80 \%$ of respondents agree with the second hypothesis.

H0: utmost $80 \%$ of respondents disagree with the second hypothesis.

With regard to z-distribution table, extent of $\mathrm{z}$ extracted from table equals to -2.33 which is less than the calculated value, whereby H0 will be confirmed. Therefore, it can say at confidence level (99\%) that over $80 \%$ of respondents have confirmed the second hypothesis.

\section{The third hypothesis testing}

Environmental component of human element affects marine accidents.

H0: at least $80 \%$ of respondents agree with the third hypothesis.

H0: utmost $80 \%$ of respondents disagree with the third hypothesis.

With regard to $\mathrm{z}$-distribution table, extent of $\mathrm{z}$ extracted from table equals to -2.33 which is less than the calculated value, whereby $\mathrm{H} 0$ will be confirmed. Therefore, it can say at confidence level (99\%) that over $80 \%$ of respondents have confirmed the third hypothesis.

\section{The fourth hypothesis testing}

bioware component of human element affects marine accidents.

H0: at least $80 \%$ of respondents agree with the third hypothesis.

H0: utmost $80 \%$ of respondents disagree with the third hypothesis.

With regard to z-distribution table, extent of $\mathrm{z}$ extracted from table equals to -2.33 which is less than the calculated value, whereby H0 will be confirmed. Therefore, it can say at confidence level (99\%) that over $80 \%$ of respondents has confirmed the fourth hypothesis.

\section{Conclusions}

Analysis of the components which affect human element has been made via Shell model which was introduced by Hawkins in 1993. Nature of this model has been grounded on this fact that the factors and problems which have enclosed the man and affected his performance and behavior should have been considered and analyzed [23] [24].

1) The first question: whether software component of human element affects marine accidents?

Analysis of the respondents' views on prepared questions in the questionnaire indicated a significant relationship between marine accidents and software components using statistical techniques. In this regards, over $90 \%$ of the individuals in statistical population have confirmed this relationship. As mentioned above, many researchers in their studies have examined the relationship between performance and other variables and have confirmed this relationship. This question and its developing components affect performance and play a major role in marine accidents [25].

2) The second question: whether hardware component of human element affects marine accidents?

Analysis of the respondents' views on prepared questions in the questionnaire indicated a significant relationship between marine accidents and hardware components using statistical techniques. In this regards, over 93\% of the individuals in statistical population have confirmed this relationship [9].

3) The third question: whether environmental component of human element affects marine accidents?

Analysis of the respondents' views on prepared questions in the questionnaire indicated a significant relationship between marine accidents and environmental components using statistical techniques. In this regards, over $85 \%$ of the individuals in statistical population have confirmed this relationship [9]. Environmental effects on 
individuals' performance were examined in detailed by researchers.

4) The fourth question: whether bioware component of human element affects marine accidents?

Analysis of the respondents' views on prepared questions in the questionnaire indicated a significant relationship between marine accidents and bioware components using statistical techniques. In this regards, over $88 \%$ of the individuals in statistical population have confirmed this relationship.

\section{Suggestions}

- Study on role of software component in behavior and performance of human element

- Study on role of hardware component in behavior and performance of human element

- Study on role of environmental component in behavior and performance of human element

- Study on role of bioware component in behavior and performance of human element

- Study on factors which derive from latent insecure conditions

- How latent factors affect work safety process

- Study human error due to work hardship at sea

- Study effective components in human error

- Study relationship between quality of training and marine accidents

- Study on role of job satisfaction in lack of marine accidents

\section{References}

[1] Khaki, Gh. (2006) How to Formulate a Plan and a Review of Research. Baztab, Tehran, Vol. 1.

[2] Safari, M., Hadi Nejad, M. and Hagh Shenas, F. (2006) Probability and Statistics in Management and Economics (Vol. II), The Sound of Light, Tehran, Vol. I.

[3] Naderi, E. and Saif Narafi, M. (1994) Research Methods and How to Evaluate It in Humanities. Badr Office of Research and Publications, Tehran, Vol. 4.

[4] Bast, J. (2006) Research Methods in Behavioral and Educational Sciences, Trans-Hassan Pasha Sharifi and Narges Taleghani. Roshd Publications, Tehran, Vol. 10.

[5] Dashgarzadeh, Kh , strategic planning resources , Aftab publication, vol. 1, Tehran , 1996

[6] Bamberger, P. and Ilan, M. (2006) Human Resources Strategy (Formulation, Implementation and Effects) dr Ali Parsaeian and dr Mohammad Arabi, Vol. 2, Cultural Research Bureau, Tehran.

[7] Farhangi, A.A. and Safarzadeh, H. (2006) Research Methods in the Humanities. Design Office of Publishing and Distribution of Books, Iran.

[8] Mirsepassi, N. (2006) Strategic Human Resource Management and Labor Relations. An Outlook with Globalization. Mir Publications Printing the New Edition of Tehran.

[9] Walton, J. (2006) Strategic Training of Human Resource, Trans-Nasser Mirsepassi and Darius GHOLAMZADEH. Human Resources Management Association Volume One g of Tehran.

[10] Ports and Shipping Organization. www.pmo.ir

[11] IRISL Website. www.irisl.net

[12] Supervisor: Dr. Asghar Moshabbeki, MA, Advisor: Dr. Ali Asghar Anvari Rostami writing Ayatollah MA Biglu (2004) Study and Environmental Stress and Its Relationship to Events and Accidents in Saipa. Master's Thesis, Tarbiat Modarres University, Tehran.

[13] Supervisor: Dr. Farajzadeh Principle, Advisor: Dr. Siavash Shayan (2006) Evaluation of Accidents and Road Safety Case Study Driven Approach to Climate Risks Karaj-Chalus. Master’s Thesis, Tarbiat Modarres University, Tehran.

[14] Folkarcl, S., Monk, T.H. and Lobban, M.C. (1978) Short and Long Term Adjustment of Circadian Rhythms in "Permanent: Night Nurses. Ergonomics, 21, 785-799. http://dx.doi.org/10.1080/00140137808931782

[15] Kleitman, N. and Jackson, D.P. (1950) Variations in Body Temperature and in Performance under Different Watch Schedules. Project NM 004005.01.02, Bethesda, Md., Naval Medical Research Institute, National Naval Medical Center.

[16] Colquhoun, W.P., Blake, M.J.F. and Edwards, R.S. (1968) Experimental Studies of Shift Work I: A Comparison of "Rotating” and "Stabilised” 4-Hour Shift Systems. Ergonomics, 11, 437-453. http://dx.doi.org/10.1080/00140136808930993

[17] RutcnI'ranz, J., Aschoi, T.J. and Maim, H. (1972) The Effects of a Cumulative Sleep Deficit, Duration of Preceding Sleep Period and Body Temperature on Multiple Choice Reaction Time. In: Aspects of Human Efficiency: Diurnal Rfivllim and Loss of Sleep, EUP, London, p. 78. 
[18] Dega, K., Dolmierski, R. and Klajman, S. (1976) Unlersiicluingen des Rliytlimus der psyclio- p!il'siologisclien Leistungsfa/iigkeit beiin Scliiffspersonal. In: Hildcbrandt, G., Ed., Biologisclie Rlivt/iinen und Arbeit, Springer Verlag.

[19] Wilkinson, R.T. (1982) The Relationship between Body Temperature and Performance across Circadian Phase Shifts. In: Brown, F.M. and Gracber, R.C., Eds., Rhythmic Aspects of Behaviour, Lawrence Eribaum Associates, 213-240.

[20] Wilkinson, R.T. (1965) Sleep Deprivation. In: Edholm, O.G. and Bacharach, A.L., Eds., The Physiology of Human Survival, Academic Press, New York, 399-430.

[21] Naitoh, P. (1969) Sleep Loss and Its Effects on Performance. Navy Medical Neuro-Psychiatric Research Unit Technical Report, No. 68-3.

[22] Tilley, A.T. and Wilkinson, R.T. (1984) The Effects of a Restricted Sleep Regime on the Composition of Sleep and on Performance. Psychophysiology, 21, 406-412. http://dx.doi.org/10.1111/j.1469-8986.1984.tb00217.x

[23] Carskadon, M.A. and Roth, T. (1991) Sleep Restriction. In: Monk, T.H., Ed., Sleep, Sleepiness and Performance, Wiley, Chichester, 155-167.

[24] Knauth, P., Landau, K., Droge, C., Schwitteck, M., Widynski, M. and Rutenfranz, J. (1980) Duration of Sleep Depending on the Type of Shift Work. International Archives of Occupational and Environmental Health, 46, 167-177. http://dx.doi.org/10.1007/BF00378195

[25] Tilley, A.J., Wilkinson, R.T., Warren, P.S.G., Watson, W.B. and Drud, M. (1982) The Sleep and Performance of Shift Workers. Human Factors, 24, 624-641.

\section{Submit or recommend next manuscript to SCIRP and we will provide best service for you:}

Accepting pre-submission inquiries through Email, Facebook, Linkedin, Twitter, etc

A wide selection of journals (inclusive of 9 subjects, more than 200 journals)

Providing a 24-hour high-quality service

User-friendly online submission system

Fair and swift peer-review system

Efficient typesetting and proofreading procedure

Display of the result of downloads and visits, as well as the number of cited articles

Maximum dissemination of your research work

Submit your manuscript at: http://papersubmission.scirp.org/ 